\title{
A reinvenção das Maculaturas realizadas por Lotus Lobo
}

\author{
Nara Firme Braga \\ Professora de Litografia na Escola Guignard, \\ Universidade do Estado de Minas Gerais, Brasil
}

DOI: https://doi.org/10.31492/2184-2043.RILP2020.37/pp.127-140

\begin{abstract}
Resumo
Neste artigo, apresentarei "As Maculaturas" da artista mineira Lotus Lobo. Maculatura era o nome dado, no passado, às chapas de folha de flandres, utilizadas tanto para teste como para acerto de impressões de embalagens de produtos nas casas de impressão comercial em litografia. Essas chapas recebiam várias impressões de diversas marcas, causando um emaranhado de imagens superpostas. A partir do estudo de Hans Belting, conhecido como "A Arqueologia da Técnica", avaliarei como Lotus, ao apropriar-se das Maculaturas e da litografia (evidenciando novamente esta velha técnica de impressão), transforma a própria litografia em arte. Analisarei, a partir das reflexões de Roland Barthes e Maria do Carmo de Freitas Veneroso, o caráter intertextual das Maculaturas, explorando as relações existentes entre palavra e imagem, a partir da "textura gráfica". Por fim, relacionarei as Maculaturas de Lotus Lobo com o trabalho do artista americano Robert Rauschenberg, com Décollage do artista italiano Mimmo Rotella e com as escrituras ancestrais dos palimpsestos.

Palavras-chave: apropriação; arqueologia da técnica; gravura ampliada; gravura contemporânea; intertextualidade; relação entre palavra e imagem.

Abstract

In this article I aim to present "The Maculatures" (Original Title: As Maculaturas), an art work by Brazilian artist Lotus Lobo. In the past, maculature was the name given to tinplate sheets used for both testing and adjusting product packaging prints in commercial lithographic printing presses. These sheets received multiple print marks of various kinds, causing a tangle of overlapping images. From the study by Hans Belting named as "The Archeology of Technique", I will evaluate how Lotus, by appropriating "The Maculatures" and lithography (highlighting again this old printing technique), transforms lithography itself into art. Based on the reflections of Roland Barthes and Maria do Carmo de Freitas Veneroso, I will analyze the intertextual character of "The Maculatures", exploring the relationships between word and image, based on the "graphic texture". Finally, I will relate Lotus Lobo's “The Maculatures" with American artist Robert Rauschenberg's works, with the Italian artist Mimmo Rotella's Décollage, and with the ancient writings of the palimpsestos.
\end{abstract}

Keywords: appropriation; archeology of technique; enlarged engraving; contemporary engraving; intertextuality; word and image relationships.

\section{Introdução}

Neste artigo, serão apresentadas "As Maculaturas" da artista plástica e gravadora Lotus Lobo, uma artista que escolheu a litografia como a poética de seu trabalho e dedica-se à pesquisa da Memória da Litografia, de sua técnica e de sua linguagem, desde a década de 60 .

Lotus nasceu em Belo Horizonte, no dia 01 de abril de 1943, graduou-se em Artes Plásticas pela Escola Guignard na Universidade do Estado de Minas Gerais (UEMG), Belo Horizonte, em 1965, e cursou disciplinas teóricas na École Superieure des Art et Industries Graphiques Estienne de Paris, nos anos de 1971 e 1972 e na École D'Art Plastiques et Sciences D'Art de L'Université de Paris, 
também nos anos de 1971 e 1972. Sua atuação como professora de litografia iniciou-se na Escola Guignard, de 1966 a 1993, onde, na mesma instituição, foi professora de gravura em metal, de 1969 a 1973. De 1974 a 1975, foi professora de Litografia na Escola de Belas Artes da Universidade Federal de Minas Gerais (UFMG).

Além disso, Lotus Lobo foi coordenadora de ateliês (oficinas) de Litografia na Casa de Gravura Largo do Ó, em Tiradentes, Minas Gerais (MG), de 1984 a 1990; na Casa Litográfica, em Belo Horizonte (MG), de 1978 a 1982; e no Grupo Oficina, em Belo Horizonte (MG), em 1964. Também coordenou os seguintes Projetos: Exposição Memória da Litografia - Acervo Lotus Lobo (2017 - 2018); Da Estamparia Litográfica - Lotus Lobo (2017 -2018); DVD Da Estamparia Litográfica - Lotus Lobo (2014 -2015); Marcas de Minas: Memória da Litografia Industrial em Minas Gerais (2014 - 2015); Memória da Litografia Industrial em Minas Gerais (1985 - 1989); O design de rótulos litográficos da Estamparia Mineira (1976).

Também vale destacar que a artista realizou várias exposições individuais e coletivas e a própria Lotus destaca como as principais exposições individuais, a saber: sua primeira exposição individual - Lotus Lobo, na Galeria Guignard, em Belo Horizonte, no ano de 1970, que marca o início de todo trabalho que a artista estava desenvolvendo com os rótulos industriais, quando pela primeira vez apresentou “As Maculaturas"; e Litografia Lotus Lobo, no Centro Cultural Minas Tênis Clube, também em Belo Horizonte, no ano de 2018, sendo essa sua mais recente exposição, onde foi apresentada uma instalação das Maculaturas, reunindo as chapas de flandres em uma nova montagem, maculaturas pertencentes a colecionadores, de acevo particulares, algumas de uma nova forma, ou seja, o outro lado das Maculaturas ainda não exibido.

\section{A reinvenção das Maculaturas realizadas por Lotus Lobo}

A partir do seu conhecimento com as pedras da oficina da Imprensa Oficial, em Belo Horizonte, que continham imagens de rótulos, de documentos fiscais, de bilhetes de loteria e de apólices e do contato direto com as matrizes e chapas de flandres da Estamparia de Juiz de Fora, que continham imagens das marcas dos produtos regionais, a artista conheceu a produção industrial iniciada no final do século XIX. Esses desenhos criados por desenhistas litógrafos europeus e artistas da região despertaram em Lotus Lobo o interesse pela pesquisa e pela preservação das imagens, como Marcio Sampaio escreveu: 
O contato com este acervo despertou de imediato o interesse da artista, por constituir-se em perfeita tradução de uma gosto que se achava profundamente arraigado no seu inconsciente, identificado como resíduo da nossa cultura afetiva e sentimental. (Sampaio, 2018/2019, p. 13).

Em sua primeira exposição individual, a artista apresentou pela primeira vez as suas Maculaturas. "A maculatura é uma placa de retificação, pois, quando a impressão sobre a placa apresenta algum defeito, a placa é suprimida e passa a ser utilizada para fazer a correção da prensa, na impressão da nova cor" (Veneroso, 2012, p. 292).

Assim, essas chapas de folha de flandres passavam a ser utilizadas para teste e para acerto das máquinas impressoras nas gráficas comerciais. Desse modo, essas chapas recebiam várias impressões de diversas marcas, causando um emaranhado de imagens superpostas. Lotus, então, apropriou-se dessas chapas de folha de flandres - As Maculaturas - e as expôs em uma galeria de arte, exatamente como ela as encontrou (Figuras 1 e 2).

Para a artista a apropriação das Maculaturas, era "um resgate de imagens que perder-se-iam no lixo. São gravuras completas, mesmo criadas por acaso" (Lobo, 2001, p. 24).

Figura 1. Painel de Maculaturas exposto na Galeria de Arte do Centro Cultural Minas Tênis Clube ( Fonte: Exposição Litografia Lotus Lobo - Galeria de Arte do Centro Cultural Minas Tênis Clube - 17 de outubro de 2018 a 02 de fevereiro de 2019 - Belo Horizonte/ Minas Gerais. Coleção da artista e coleções particulares).

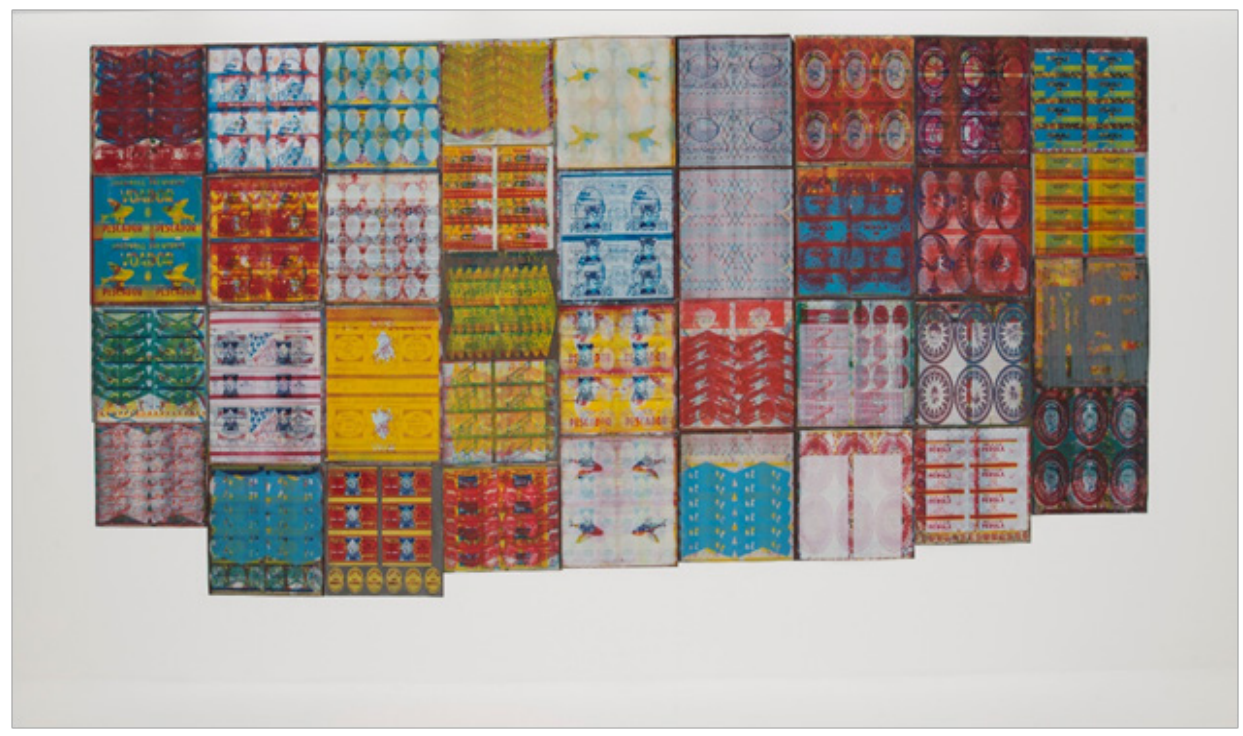


Figura 2. Lotus Lobo - sem título - da Estamparia Litográfica Maculatura sobre folha de flandres. Litografia - 1970/2018 (Fonte: Acervo pessoal).

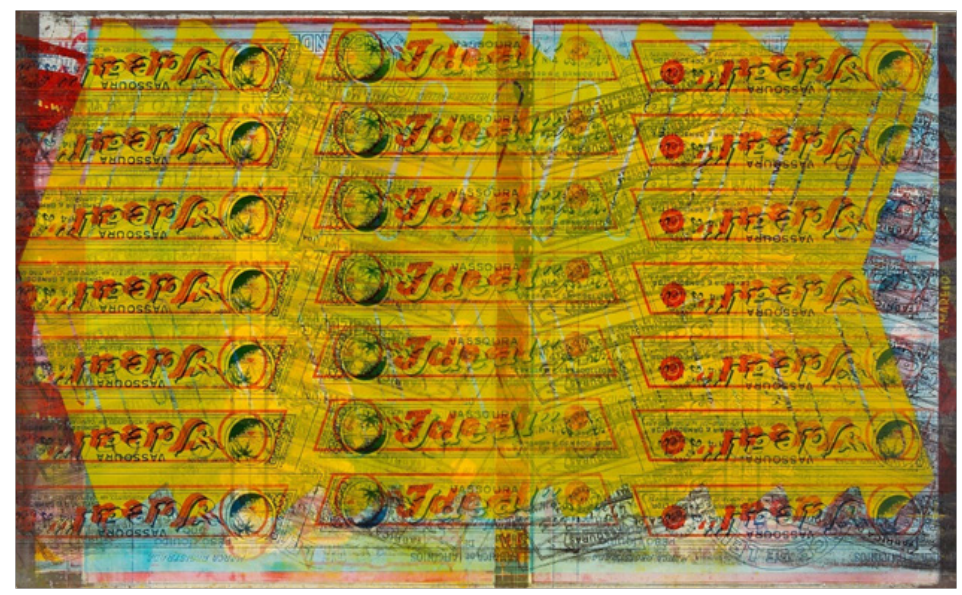

Nas Maculaturas apropriadas por Lotus Lobo, com as sucessivas impressões realizadas umas sobre as outras, para acerto das máquinas impressoras sobre as chapas de flandres, percebo que ocorreu, ao mesmo tempo, a soma das cores das marcas e das molduras dos produtos misturadas às palavras. Essas, por sua vez, tornam-se quase ilegíveis, evidenciando uma nova visualidade da letra, como se fossem palavras bordadas, numa aproximação com a pintura, digna do próprio nome das casas de impressão litográficas, Estamparia, evidenciando o caráter intertextual presente nas Maculaturas, no qual palavra e imagem dialogam entre si, rompendo os limites entre as linguagens, assumindo novas leituras, como Maria do Carmo de Freitas Veneroso avaliou:

\footnotetext{
Neste sentido, a leitura de textos e poetas e de artistas plásticos pode ser feita através do tecido visual, da sua "textura gráfica", no sentido barthesiano. Ao se referir à textura gráfica, Barthes traça uma relação com a origem da escrita, numa época em que desenhar, gravar, escrever eram atividades muito próximas (Veneroso, 2012, p. 87).
}

As relações entre palavra e imagem presentes nas Maculaturas reforçam o caráter tanto visual quanto intertextual da letra, da marca dos produtos, da marca da letra de cada produto - "o espírito da letra", dessa potencialidade e do vigor da imagem da letra, que Lotus também se apropria, dos diferentes tipos de letras criadas e desenhadas pelos calígrafos responsáveis pelo desenho das letras das marcas litográficas. E “[...] esses caracteres nada mais são do que a combinação de algumas retas e de algumas curvas; mas, por um lado, é o ponto de partida de um enorme conjunto de imagens, vasto como uma cosmografia" (Barthes, 1990, p. 93). 
O desenho das letras realizados por esses calígrafos exerceram papel fundamental para a criação das marcas dos produtos, evidenciando e comprovando a "força da letra", a força dos desenhos das letras sobre as marcas dos produtos, notabilizando esse caráter identificador das marcas, da robustez da letra, que nomeiam o produto, que definem a propriedade da marca. Compartilho o que Barthes escreve em seu texto "O Espírito da Letra", onde o desenho da letra, a imagem da letra, seu significado e símbolo reforçam o "espírito da letra", que vivifica esse símbolo da letra.

[...] por um lado, o extremo prazer (toda a poesia, todo o inconsciente são uma volta à letra); diz respeito simultaneamente ao grafista, ao filólogo, ao pintor, ao jurista, ao publicitário, ao psicanalista, e ao estudante. A letra mata e ao espírito vivifica? Seria simples, se não existisse precisamente um espírito da letra, que a vivifica; ou ainda, se o símbolo por excelência não fosse a própria letra. É precisamente esse trajeto circular da letra, que nos mostra Massin [...] (Barthes, 1990, p. 93).

Na Maculatura da Figura 3, onde foram impressas coincidentemente duas marcas de sardinhas prensadas - Voador e Pescador -, ocorreu a sobreposição de impressão dessas marcas. A intensidade dos desenhos das letras das duas marcas se iguala no sentido de sua expressividade e de seu vigor, parecendo surgir uma nova marca de produto - Sardinhas Prensadas Voador Pescador. Esse caráter visual da letra (re)cria uma nova marca, um novo produto, uma reinvenção das marcas pelo olhar da artista.

Todos citados por Massin, monges, grafistas, litógrafos, pintores, fecharam o caminho que parece levar, naturalmente, da primeira a segunda articulação, da letra à palavra, e tomaram outro caminho, que é o caminho da não linguagem, mas da escrita, não da comunicação, mas da significância: aventura que se situa à margem das pretensas finalidades da linguagem, e, justamente por isso, no centro de sua ação (Barthes, 1990, p. 94).

Figura 3. Lotus Lobo - sem título - da Estamparia Litográfica Maculatura sobre folha de flandres. Litografia - 1970/2018. Fonte: Coleção Bruno Assumpção.

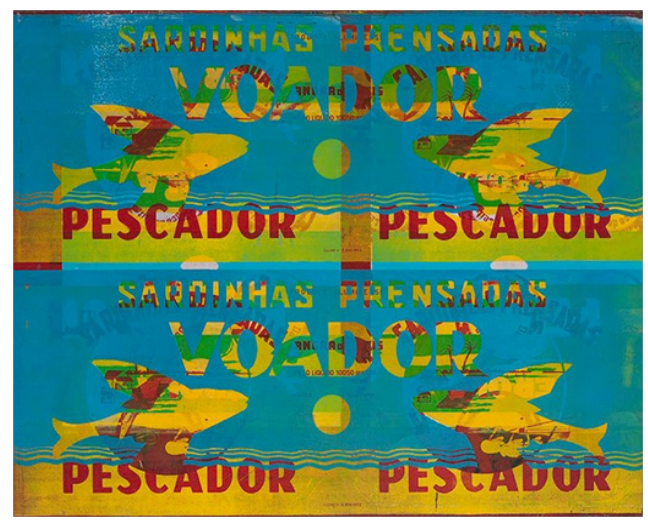


Márcio Sampaio, crítico de arte e escritor, diz que Lotus, ao se apropriar das Maculaturas, revela para o mundo da arte o gosto peculiar e os costumes das Minas Gerais, expondo para o público a estética caipira, a importância histórica da memória da litografia e dos desenhistas europeus e a influência de Minas sobre eles, criando um design tipicamente mineiro para os produtos.

$\mathrm{Na}$ Maculatura apresentada na Figura 4, percebemos a sobreposição e a combinação de três tipos de letras e de duas marcas de produtos: a marca do doce de leite Borboleta e da marca de vassouras Ideal. A imagem torna-se única, uma gravura única, com a combinação de letras diferentes, que compõem uma imagem. "Seu trabalho discute a própria linguagem gráfica - as letras, as marcas - todo esse universo no qual ela circula, que é extremamente gráfico: é a letra/imagem, sua marca" (Veneroso, 2012, p. 291).

Figura 4. Lotus Lobo - sem título - da Estamparia Litográfica Maculatura sobre folha de flandres. Litografia - 1970/2018. Fonte: Coleção Lauar.

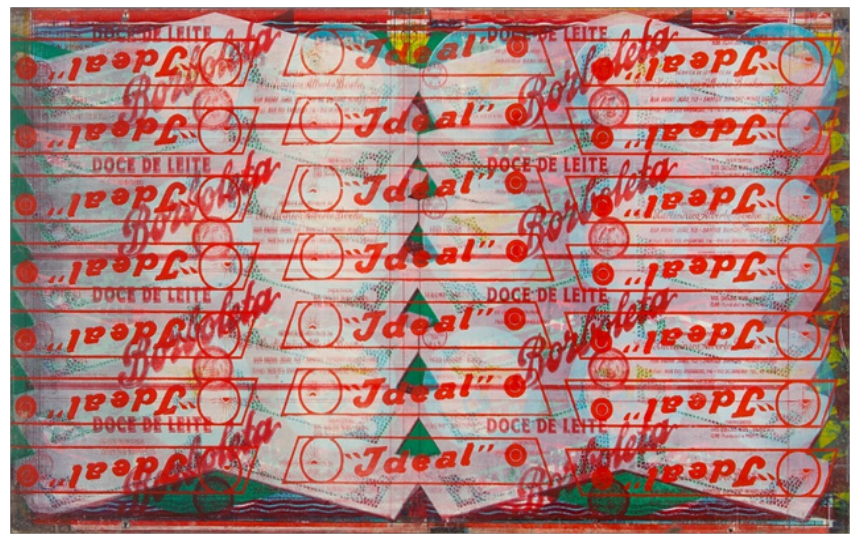

Figura 5. Lotus Lobo - sem título - da Estamparia Litográfica Maculatura sobre folha de flandres. Litografia - 1970/2018. Fonte: Coleção Hallisom Moreira.

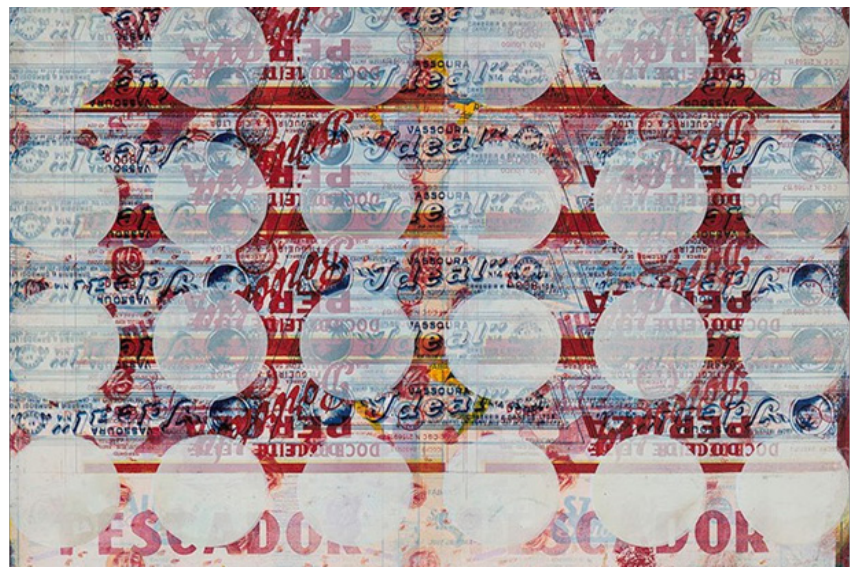


Na Maculatura da Figura 5, têm-se a impressão e a sobreposição de letras e marcas de produtos como da vassoura Ideal, a marca do doce de leite Borboleta, a letra da marca de sardinhas Pescador. Nela, nota-se que a leitura (o olhar da artista) realizada por Lotus Lobo foi percebida por meio da "textura gráfica". São Impressões de várias letras/marcas.

Assim, Lotus reinventou as Maculaturas, transformando o que se destinaria a ser parede, teto e muro da casa de pessoas carentes em paredes de uma galeria de arte:

De Minas seu paciente lavrar: Minas agrária. Minas de bois e vacas. Minas pasto, Minas taipa e caliça. Minas de leite, queijo e manteiga. Minas caturra, Minas das Gerais. O primeiro gesto de Lotus determinou a arte: tomar o lixo (folha de flandres) da impressora, como os pobres o tomam para fazer a parede da casa, o teto, o muro [...] A estética do princípio do século, caipira, renasce nas estamparias litográficas de Lotus, trazendo um gosto que se faz novo ao novo sol: arte (vida) em forma de lixo, cores, palavras, desenganos, há muito esquecida na prateleira do tempo e revivida agora com o gesto da artista (Sampaio, 2018/2019, p. 293).

O conceito de uma gravura original no trabalho de Lotus Lobo é também discutido por meio de sua apropriação das chapas de flandres por ela encontradas nas antigas casas litográficas. O que antes se destinaria a outros rumos, como piso e até mesmo lixo, ela retira das antigas casas de impressão e leva para o mundo da arte, transfigurando e reinventando o conceito das Maculaturas, designando-as como gravuras completas e únicas, ampliando o conceito de gravura.

Desse modo, as definições estabelecidas sobre uma "gravura original", propostas pelo Print Council of America, agência que decidia a maioria das regras e regulamentos sobre gravuras nos Estados Unidos, como "o artista, sozinho, criaria a imagem mestre sobre ou na placa, pedra, bloco de madeira ou outros materiais, com o objetivo de criar uma gravura", "a gravura é feita dos materiais citados, pelo artista, ou conforme sua direção" e "a gravura final é aprovada pelo artista" (Knigin, s/d, p. 2), não se encaixam nessa "nova modalidade de gravura". Assim, concordo com o que Maria do Carmo de Freitas Veneroso afirma sobre o conceito ampliado de gravura original:

Porém, essa definição não abrange os processos fotográficos nem as imagens apropriadas, frequentemente exploradas pelos gravadores nas últimas décadas. Com o surgimento dos processos fotomecânicos e da apropriação de imagens preexistentes, a gravura original teve de ser redefinida. Assim, seu conceito ampliou-se, a fim de abarcar as imagens fotográficas, a cópia única e as imagens apropriadas, não necessariamente feitas pela mão do artista, e também as imagens processadas no computador. Existe ainda a questão da gravura tridimensional, quando a própria matriz é apresentada como obra (Veneroso, 2009, p. 148). 
Ao se apropriar da litografia industrial mineira, percebe-se também a repercussão e a influência da Pop Art na obra de Lotus Lobo, levando para o mundo da arte o imaginário da cultura popular rural de Minas Gerais e também a própria investigação da técnica de reprodução litográfica. Esse caráter reprodutivo não só aproximava-se de Andy Warhol como também das experimentações de novos suportes e das superposições das imagens, como em Rauschenberg. Desse modo, Lotus apresenta marcas de embalagens de manteiga, banha, fumo, nomes de mulheres, cidades, pássaros, etc. Luciano Gusmão, grande impulsionador dos primeiros trabalhos litográficos de Lotus, descreveu no release de sua primeira exposição individual esse caráter da Pop Art nas obras da artista:

Uma velha técnica de impressão, como a litografia, pode vir a ser uma nova técnica de imagem? O caráter de novidade de uma técnica não se verifica apenas no confronto com técnicas tradicionais: no contexto do consumo (artístico ou não) a novidade é uma questão de estrutura, um modo imprevisível de arranjar as coisas. Lotus apropria: o contexto desta apropriação é a litografia industrial mineira entre 1920 e 1950. Apropria marcas-embalagens de manteiga, banha, queijo para pequenos produtores, pequenos consumos, das margens do São Francisco à Zona da Mata. É toda uma geografia que se reestrutura, mapa de palavras cidades, os caminhos de ferro, as várzeas, os bois: São Miguel de Guanhães, Almenara, Araçuari, Patos de Minas, Cordisburgo, Januária, Dores do Indaiá. Trabalhando na visualidade dos produtos, as marcas exploram o repertório da cultura dos consumidores, em busca de motivações: nomes de mulheres (Célia, Zina, Nhanhâ, Ivone, Madalena, Marilene); de deusas (Minervina, Vênus, Artemisa); de pássaros (Andorinha, Gaivota Branca, Caturrita, Avestruz, Macuco); de lugares, nomes inventados (Palpite, Pedra Azul, Pinherinha, Donzela, Flor da Bahia); nomes-de-homenagem. As imagens descrevem paisagens de outros lugares, templos gregos, paisagens de folhinha (Gusmão, 1970, p. 1).

Ao se apropriar e ao expor as Maculaturas da Estamparia Juiz de Fora, Lotus transformou a própria técnica da litografia em arte, exibindo para o público as chapas de testes realizadas pelos impressores por acaso nas casas de litografia comercial em Minas Gerais, no passado. Percebo que Lotus, ao encontrar essas chapas, entende que elas evidenciavam não só a beleza estética em si, mas, também, que na impressão para os ajustes das máquinas impressoras, com a sobreposição de várias marcas nas mesmas chapas, efetuava-se uma metamorfose das próprias marcas, transmutando essas marcas, criando novas imagens, novas leituras, verdadeiras gravuras e novas marcas, reinventando-as. Desse modo, a arte está na própria técnica, no próprio meio - a litografia -, por apresentar a sobreposição das imagens, e também pelo que acontece com a soma, as misturas cromáticas acontecem. Por isso, concordo com o que Hans Belting aponta sobre a importância de uma velha técnica, na produção de artistas contemporâneos, que se apropriam de técnicas obsoletas: 
A decisão sobre a arte na pós-história é tomada ali onde se quer transformar a própria técnica em arte: no produto de uma fantasia já metatécnica. Não se pode falar ainda de uma era pós-técnica, mesmo que a técnica já seja agora um domínio com uma história própria, de modo que vemos surgir recordações e citações através da antiga técnica, isto é, uma arqueologia da técnica (Belting, 2006, p. 275).

Lotus Lobo, além de evidenciar ao mundo da arte as Maculaturas, traz uma velha técnica de impressão novamente em evidência.

\begin{abstract}
A inovação permanece um desejo, que hoje se realiza pela mudança do médium a da técnica. Ao escolher, por exemplo, em vez de quadros de videoinstalação, pode-se até mesmo citar quadros antigos, sem com isso cair imediatamente sob o veredicto da imitação. Enquanto se permaneceu no mesmo médium, a novidade só podia ser alcançada às custas da dessemelhança com os modelos existentes. Era preciso produzir o novo sempre com meios antigos. Hoje o novo está mais na escolha dos meios, mais do que no conteúdo e da ideia (Belting, 2006, p. 275).
\end{abstract}

Relaciono o trabalho de apropriação das Maculaturas e também da apropriação da técnica da litografia que Lotus opera com o que Hans Belting coloca abaixo. Percebo que a própria técnica da litografia ensinou muito à Lotus, pois, a partir desse encontro com a litografia, ela pesquisou, observou e aprendeu com o que a técnica pode proporcionar. De certa forma, houve, para Lotus, "o legado das Maculaturas", como Belting aponta:

\footnotetext{
Por um lado, cresce utopia de dissolver a arte na pura técnica e de abolir, definitivamente, desse modo, a expressão de si do homem. Por outro lado, surge aos poucos o discernimento de que a técnica também proporciona agora meios de expressão pessoal com os quais o artista pode trabalhar do mesmo modo como antes trabalhou com o pincel e a paleta (Belting, 2006, p. 275).
}

Relaciono, abaixo, as Maculaturas de Lotus Lobo com a obra do artista americano Robert Rauschenberg, participante da Pop Art americana, movimento que teve mais influência em Belo Horizonte, e com o artista italiano Mimmo Rotella, que fazia parte do Novo Realismo, pois a obra de ambos os artistas relacionam-se com as Maculaturas de Lotus Lobo (Figura 6).

Robert Rauschenberg denomina sua pintura de Combine-Painting, porque, nela, ele combina coisas de verdade: cadeiras, pneus de carro, animais empalhados, fotografias recortadas de jornais, reproduções de obra de arte, etc. Apropria-se do que interessa e insere em suas pinturas gravuras, combinando uma coisa com as outras. Em Rauschenberg, "as coisas" encontradas por ele são guardadas em seu estúdio para serem usadas posteriormente em uma nova obra, fragmentos de sua paisagem habitual, restos e refugos das ruas de Nova York. 
Figura 6. Robert Rauschenberg (1925-2008) - Oil and silkscreen ink on canvas/tinta a óleo e serigrafia sobre tela, $96 \times 72$ in. (243.8 x $183.8 \mathrm{~cm}$.), 1964. Fonte: https://www.christies.com/lotfinder/ Lot/robert-rauschenberg-1925-2008-buffalo-ii-6205129-details.aspx

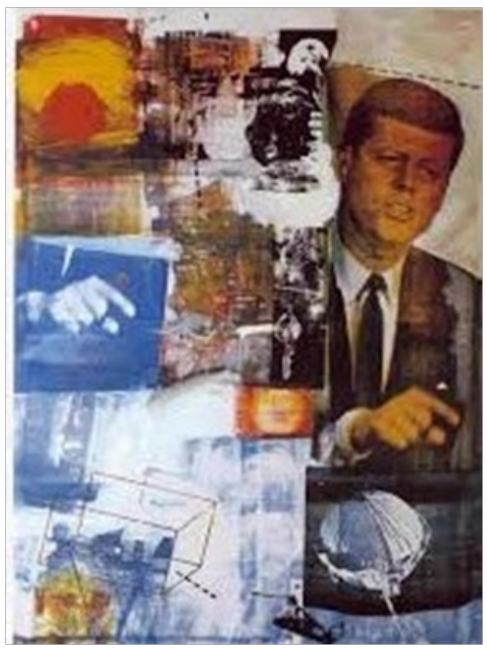

Entre o trabalho de Lotus Lobo e o de Robert Rauschenberg, percebo a questão da apropriação de coisas encontradas, do que não interessa mais, das coisas descartadas, que se destinariam ao lixo. Rauschenberg utiliza em seus trabalhos coisas do passado, referencia obras-primas passadas, assim como Lotus referencia as Maculaturas da Estamparia Juiz de Fora. A superposição de imagens, a utilização da visualidade da letra, resgatando a memória do que já passou, estão presentes nesses dois artistas. Lotus retira a história da litografia em Minas, do passado para o presente, em um sentimento de preservação, enquanto Rauschenberg recupera em seus trabalhos imagens da cultura de massa, reutilizando os refugos, como Argan relata em seu livro:

\footnotetext{
É sua frequente referência a uma sociedade que conhece apenas o presente, e não tem piedade pelo que não precisa mais, pelo que é passado. Excluindo desse presente, que, ademais, não o que interessa, ao artista resta apenas manipular o passado, reutilizar os refugos, salvando-os, salva-se a si mesmo da condição de "refugo" a que é lançado pela sociedade. Não se explicaria sua frequente referência às obras-primas do passado (ainda que fanadas reproduções correntes) sem uma melancólica nostalgia por aquela que foi, e já não pode mais ser, a profissão de artista. Para ele não existe história que situe as lembranças numa perspectiva clara; essas obras primas não passam de recordações misturadas, confusas emaranhadas com muitas outras (Argan, 1992, p. 642-643).
}

Mimmo Rotella, com os seus Décollage, executados com fragmentos de cartazes publicitários, repara no gesto instintivo de arrancar os cartazes de propaganda, principalmente os anúncios de cinema retirados e recobertos por outros 
(Figura 7). O cartaz rasgado, que deixa surgirem as figuras ou as palavras dos cartazes por baixo, revela um emaranhado de fragmentos de notícias sem nenhuma relação entre si. Neste momento, a imagem já não tem a conotação publicitária e ela pode ser vista como imagem.

Figura 7. Mimo Rotella; Marilyn; Décollage; 1963; 1,90 x 1,32; Galeria Stein. Fonte: Argan, 1992.

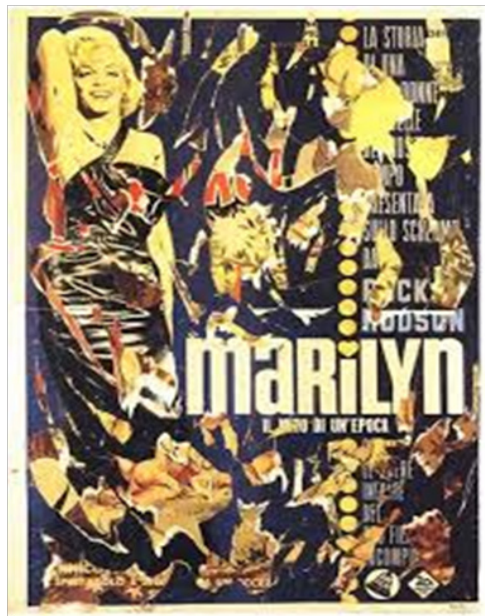

Relaciono as Maculaturas de Lotus Lobo com os Décollage de Mimmo Rote1la. Lotus observou as impressões sobre impressões de várias marcas, letras, cores e molduras, vários desenhos e produtos e várias histórias nas Maculaturas das casas de impressão comercial, transparecendo nas chapas de flandres, por meio das sucessividades de marcas, o que foi impresso antes. Mimmo Rotella nota, de certa forma, o contrário, ao olhar para os cartazes publicitários que são colados um sobre o outro e arrancados e rasgados pela população em um gesto instintivo e que revelam o que está por baixo, descobrindo várias imagens, figuras e imagens que estavam cobertas e vários fragmentos das letras, como Argan destacou:

[...] há uma relação entre esse aparato de imagens coloridas e a neurose do habitante da cidade. Há algo mais: a publicidade é informação, é o instrumento essencial da civilização de consumo. Todavia, o cartaz rasgado, que deixa aflorar, como um palimpsesto, as figuras dos cartazes por baixo, transmite uma miscelânea de fragmentos de notícias sem nenhuma ligação ou relação entre si. Exatamente porque a imagem já não serve mais a sua função publicitária, ela pode ser vista como imagem, avaliada como fato estético [...] (Argan, 1992, p. 643).

Faço uma analogia entre os palimpsestos e as Maculaturas apropriadas por Lotus Lobo. Enquanto que nos palimpsestos as escrituras ancestrais se revelam por meio de uma nova gravação ou uma nova escritura, nas Maculaturas percebo 
que as impressões anteriores também deixam transparecer por trás de uma nova impressão, uma nova marca, uma nova letra em um mesmo suporte. Assim, a reutilização do mesmo suporte que acontece entre essas duas técnicas, demonstram sobreposições de várias impressões e revelações de antigas e novas gravações de várias escrituras, letras, histórias e orações e vários textos antigos (Figura 8).

Figura 8. Palimpsesto - Codex ephremi.

Fonte: https://pt.wikipedia.org/wiki/Codex_Ephraemi_Rescriptus.

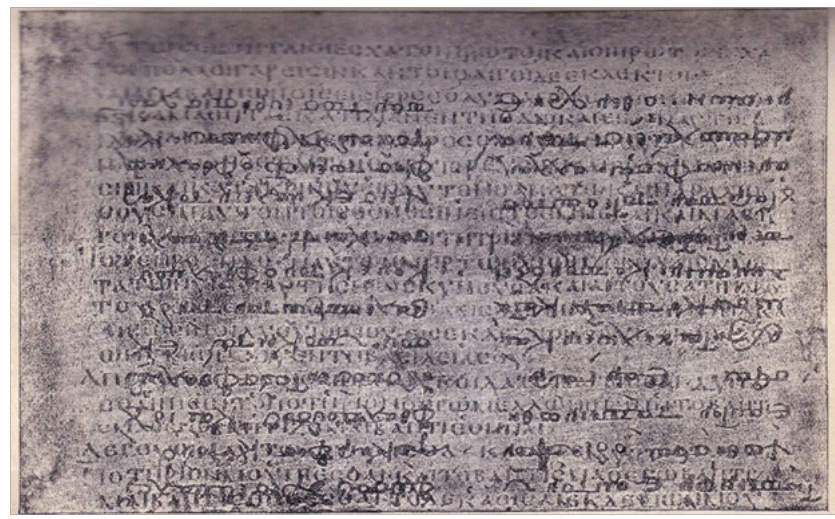

Enquanto nos palimpsestos revela-se a escritura anterior com novas escrituras sobrepostas, nas Maculaturas de Lotus Lobo a impressão de várias marcas, rótulos, letras, revelam-se por meio de uma nova impressão.

Percebo, também, a relação intertextual entre os palimpsestos e as Maculaturas, afirmando o caráter visual das escrituras, das letras, das marcas dos produtos, tornando-se tudo imagem, por meio da "textura gráfica", no sentido barthesiano, como já foi citado acima. Assim, "todo um catálogo dos produtos naturais e humanos vem duplicar a curta lista do alfabeto: o mundo inteiro incorpora-se à letra, a letra torna-se imagem na tela do mundo" (Barthes, 1990, p. 94).

\section{Conclusão}

A artista e gravadora Helena Kanaan (Porto Alegre - Rio Grande do Sul), escreveu a respeito da sobrevivência das imagens, citando o filósofo George Didi-Huberman, o que torna uma imagem sobrevivente durante anos, séculos na história, e que os artistas, assim como suas técnicas, perpetuam por meio da imagem, tornando-as vivas, no passado, no presente e no futuro.

Diante de uma imagem, temos que humildemente reconhecer que ela provavelmente nos sobreviverá, que frente a ela nós somos frágeis, ela nos direciona a uma pensamento de passagem, ela é o nosso elemento do futuro, elemento de duração. "Olhá-las é desejá-las, é esperar, é estar diante do tempo. 
Porém que classe do tempo? De que plasticidades e de faturas, de que ritmos e de que golpes do tempo.” pode tratar-se?" (Didi-Huberman, 2015, p.15). Elas contêm passado, presente e futuro. Então, como dar conta de todos esses tempos frente a uma obra? Da memória convocada e do futuro que se abre? (Kanaan, 2018, p. 70).

Percebo essa eternização das imagens ao longo do tempo, pelo olhar da artista Lotus Lobo ao encontrar com as Maculaturas, pelos antigos, por meio dos palimpsestos com suas escrituras, pelo olhar observador de Mimo Rotella sobre os fragmentos de cartazes arrancados, pelas combinações de Robert Rauschenberg. Todos esses artistas e suas obras evidenciam a visualidade da letra, reforçam o caráter visual e intertextual da letra como imagem, apropriam-se de imagens preexistentes.

\section{Imagens}

As imagens das Maculaturas foram gentilmente cedidas pela artista Lotus Lobo.

Fotografia das Maculaturas - Lucas Galeno.

\section{Agradecimentos}

Agradecimentos à Lotus Lobo, a Guilherme Machado, à Márcia Renó e a Lucas Galeno.

\section{Referências}

Argan, G.C (1992). Arte Moderna. São Paulo: Companhia das Letras.

Barthes, R. (1990). O óbvio e o obtuso. Rio de Janeiro: Nova Fronteira.

Belting, H. (2006). O fim da história da arte: uma revisão dez anos depois. São Paulo: Cosac e Naify.

Didi-Huberman, G. (2015) Diante do tempo: História da arte e anacronismo das imagens. Belo Horizonte: UFMG Hidalgo.

Kanaan, H. (2018). Intervalos: entre a gravura e a música, uma curadoria para Nilza Haertel. In: Salvatori, M. Maristela, Kanaan, H. (org.). Experimentações gráficas de Nilza Haertel: recorte de um acervo. Porto Alegre: Marcavisual. pp. 65-72.

Kning, M. (s.d). The mylar method of lithografy. Texto inédito.

Gusmão, L. (1970). Release para a primeira mostra individual de Lotus Lobo. Belo Horizonte: Galeria Guignard.

Lobo, L. (2001). Depoimento. Belo Horizonte: Editora C/ Arte.

Sampaio, M. (2019). Catálogo da exposição apresentada na Galeria de Arte do Centro Cultural Minas Tênis Clube, realizada entre os dias 17 de outubro de 2018 a 02 de fevereiro. 
Veneroso, M. do C. de F. (2012). Caligrafias e Escrituras. Belo Horizonte: Editora C/ Arte.

Veneroso, M. do C. de F. (2009). A gravura no "campo ampliado": relações entre palavra e imagem na gravura, gravura e fotografia e gravura tridimensional na contemporaneidade. In: Veneroso, M. do C. de F., Melendi, M. A (org.). Diálogos entre linguagens. Belo Horizonte: Editora C/Arte. pp. 145-159.

Data receção: 16/09/2019

Data aprovação: $31 / 03 / 2020$ 